\title{
A Matrix Approach to Position Classification
}

\begin{abstract}
This article presents the results of a study prepared in connection with the development of a classification system for librarians in the University of Western Ontario. The study employs the formulation and application of four "general" and five "ranking" factors in position classification; the development of a matrix using the above factors on a vertical axis and the desired number of positions on a horizontal axis; and the analysis of all existing professional positions in terms of the matrix. Administrative implementation of the findings is also described, including the appeals procedures established.
\end{abstract}

E

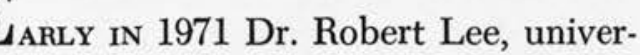
sity chief librarian of the University of Western Ontario, Canada (UWO), invited Dr. John Wilkinson and Dr. Kenneth Plate of the University of Toronto Faculty of Library Science to consult with his administrative group and with representatives of the Librarians' Association of the UWO Library System in order to develop a classification program for librarians in that system. The following paper is a result of the ensuing cooperation between the two consultants, Dr. Lee, and many members of his professional staff.

The Purpose of Reviewing a

Classification Program for Professional Positions

This paper presents in brief a somewhat different approach to position classification for librarians. This approach -while developed specifically for the

John Wilkinson and Kenneth Plate are members of the Faculty of Library Science, University of Toronto, and Robert Lee is university chief librarian, University of Western Ontario, London, Ontario.
UWO system, which is considered to be relatively advanced in its management by objectives concepts and in the strength of its management at all levels -can be applied to all types of medium-sized and large library organizations. Indeed, the approach involved the formulation and application of a schemata of "general" and "ranking" position characteristics which may have considerable theoretical as well as practical interest for librarians. Insofar as the analysis is of interest, it will also be controversial; but controversy is the crucible of philosophy, and librarianship, we may at least agree, is long overdue for a philosophy of its own.

Nothing is more central to the health of a library organization than the motivation of its staff. Nothing is more detrimental to that motivation than an irrational position classification. Given that relatively large and complex organizations apparently require at least a modicum of hierarchical stability, it does not follow that such stability can be achieved through administrative fiat alone. Indeed, in a society more and more influenced by concepts of egalitar- 
ianism and specialization, the legitimacy of externally imposed power is being increasingly challenged. No longer is the dictate that a superior position exists by virtue of its superiority-that a department head is a department head is a department head-wholly acceptable to a subordinate possessing specialized skills and the knowledge of having made an important contribution to an organization. Nor should administrative authority as such be acceptable in a healthy organization-particularly if that organization includes a strong "professional" element. Some other rationale for position classification and hierarchical development is clearly needed.

We will not here become involved in the increasingly tiresome debate as to the nature of professionalism, except to note that, however we define "professionals," the concept of a specialized body of knowledge and consequently of "expertise" seems inevitably to develop. It is important at this point to note also that nothing in the definition of "professional" nor in the application of the general factors proposed in this paper should be construed as being derogatory to support positions. The constants used are merely delineators. A support position may clearly be more valuable to an organization than a professional position in a given context.

A defensible position classification must attempt to optimize the use of human resources. A defensible professional position classification must rationalize, first, the optimum use of professional personnel as distinct from support staff and, second, the ranking of professional positions on an ordinal scale in terms of key factors of professional service.

First, unless the classification program clearly distinguishes between professionals and support staff, it cannot be justified as a professional position classification; and its application may indeed destroy the professional nature of the organization. Second, unless the program leads to a rational, viable, and easily justifiable ordinal ranking of professional positions, it can have little value as a classification tool.

The following approach meets the first criterion in that it identifies those characteristics which should be common to all professional positions and which, in total, delineate such positions from support positions on the one hand and from administrative positions on the other. These factors are here termed "general factors."

The approach meets the second criterion in that it identifies those factors, distinct from the general ones, which should show greater development as the levels of positions in the classification schedule rise, and which may, therefore, be used to rank positions in a broad classification scheme. These factors are here termed "ranking factors," and they are significantly characterized by their quality of continuum growth which enables them to alter in degree but not in kind as the continuum nears the upper levels of the schedule. Ranking factors, therefore, may be viewed as developmental stages in a given continuum.

There are a number of studies in the literature of librarianship useful in constructing a position classification program. Two studies, the first by Rothenberg et al. and the other by Ricking and Booth, provide definite statements useful in distinguishing between professional and nonprofessional tasks., 2 These ground-breaking studies do not, however, attempt to enunciate distinctions between the levels of professional positions. In an article published in 1965, Downs and Delzell also emphasize the differences between professional and nonprofessional tasks. ${ }^{3}$ In addition, they describe what librarians do at various levels, using examples from the universities of California, Michigan, and Illinois and the U.S. Civil Service Commission. The elements of position classi- 
fication for librarians as presented in the Downs and Delzell article were useful in our preliminary planning at the University of Western Ontario. However, in terms of the present study, two major drawbacks were identified: (1) Because of the modified management by objectives philosophy of library management at the University of Western Ontario, such elements as "supervisory responsibility" had necessarily to be deemphasized. Furthermore, provision had to be made for a team approach to problem solving, with emphasis on planning and development and with distinctions made between projects and programs. (2) The elements or factors used in the examples presented by Downs and Delzell were not always present in differing amounts in the position levels described in the present study.

The best report of a library position classification program to date is the article by Tompkins describing the method by which positions were classified at the University of Michigan. ${ }^{4}$ Tompkins and her committee opted for the point rating system, a quantitative system that yields a numerical score which can be translated into a classification level. The principal advantage of such a quantitative approach is that it apparently develops a "precision of applicability," i.e., that it can be applied in a scientific manner. ${ }^{5}$ Appearances may however, of course, be deceptive and "research results ... . show that less complex systems yield results almost identical with complicated systems. . . ."6 Bearing in mind that the principal disadvantage of a quantitative system such as that used at Michigan is the amount of time required for its conception and implementation, one must decide whether the extra time and expense in terms of the relevant precision achieved can be justified. Tompkins notes that an average of thirty interviewer's hours was necessary to describe each position using this system for 105 positions! She notes further that "twenty-one months after its inception, the committee held its forty-eighth and final meeting." " It was soon decided at UWO that, based on Tompkin's experience, we could not justify such an extended and costly program without more conclusive evidence that superior results would ensue. The factors used at Western do, however, bear some similarity to those selected for use at Michigan with the important difference that the management by objectives approach at UWO precluded using some of the traditional yardsticks of position classification. For example, Michigan's “independence of performance" factor is developed through the five grades in terms of freedom from supervision, whereas the "independence and freedom of action" factor in the present matrix is developed in terms of systems constraints (projects, programs, and objectives) as these relate to individual positions. Another example involves problem solving and decision making. Here Michigan's classification assumes a larger number of problems which become more complex at the higher end of the scale. While this is undoubtedly true of most organizations, the introduction of management by objectives diffuses the locus of complex problems through many levels. What determines the level of a position in the present study in this regard is whether general participation in problem solving is required or whether a position carries specific responsibility for problem solving and planning and whether for tasks or projects, programs or policy, and ultimate approval or veto.

\section{IDENTIFYING AND DEFINING THE}

Factors in Position Classification

\section{General Factors}

The general attributes which distinguish all professional positions are four in number. Basic academic qualifications form one such factor. The basic library science degree represents basic 
professional expertise and potential for promotability (in the case of a position requiring a professional specialist who is not a librarian, the appropriate degree would be the equivalent of the B.L.S. or M.L.S.). Arguments concerning the quality of relevant professional education do not apply in this instance, because no other generally accepted baseline for professional expertise has thus far been developed. However, as with all the general factors in this approach, the requirement of basic academic qualifications cannot alone be considered as justification for ranking a position as professional.

Judgment is a second general factor. Judgment, in the professional context, involves the application of expertise to the reasoned and defensible analysis of alternatives in order to determine a preferable course of action. A position must require frequent application of such expertise in order to be regarded as professional. It is recognized, of course, that some degree of judgment is concomitant with survival, on the job or off it; but, whereas the clerical's exercise of judgment is normally circumscribed and assisted by established routines, the judgment of the professional should be less dependent upon precedent than upon comparative knowledge and expertise. Unless decision making involving the adjudged choice between alternatives as described above is present as a normal element of a position, the need to exercise the basic expertise already specified as the rationale for including basic academic qualifications as a general factor is absent. Judgment, therefore, is that factor which exercises the latent force of relevant substantive education.

Client relationships, the third general factor, are a hallmark of all established professions. Without such relationships, which carry with them a mentor connotation, professional expertise is not utilized on a one-to-one service basis. The client relationship, embodying as it does interpersonal change and enrichment, has indeed traditionally been one of the qualities distinguishing professional expertise from creative skills. Once again it is important to realize that the client relationship is a general factor in part because it implements other general factors. The requirement of client relationships in a position does not alone rank that position as professional.

Voluntary involvement in professional activities is a general factor common to all professional positions. It would be unusual to find such involvement as a formal requirement of a position; but, leaving aside the question of the adequacy of professional associations, it is highly unlikely that professional development in a position can occur without the type of formal external contacts represented by professional associations and other forms of continuing self-education. A position that does not involve from time to time external professional activities as an enriching and necessary element is unlikely to be a viable professional position in terms of the other general factors discussed above.

All the preceding factors-basic academic qualifications, judgment, client relationships, and involvement in professional activities-are general to all professional positions. Their joint presence distinguishes such positions from support positions; but alone they are not viable instruments for ranking positions because they are not themselves capable of being conceived of on a consistent growth continuum. Thus, for example, while additional academic and professional degrees represent evidence of additional expertise and may indicate suitability for promotion, the minimum number of degrees required by a position-stated as such and without reference to the degree of expertise required by a position-is not a ranking factor because it is a given constant. 
(By analogy, we may determine that a lamp must give light to be a lamp; but we cannot usefully extrapolate from this general factor to rank all lamps by the degree of light they give. An object that does not give light, we may agree, is not by definition a lamp, but for certain purposes a dim light may be much "better" than a bright light.)

Ranking factors are context-oriented; whereas general factors are arbitrary. Thus, scope for judgment may increase as the scope of responsibility and accountability increases; but the quality of judgment is an unrankable constant. The same is true of client relationships, although the level of external contacts can, as we shall see, be used as a criterion for ranking.

\section{Ranking Factors}

The development of ranking factors is based on four assumptions. One we have already noted-that medium and large-sized organizations do need the stability provided by hierarchical ranking. The second assumption is that ranking must be based upon demonstrably relevant factors which can be severally extended on a logical continuum. The third assumption is that arbitrary administrative designations are not, as such, demonstrably relevant to the objectives of modern library organizations, and that such designations are not viable over an extended continuum. The fourth assumption is that ranking factors for professional positions must relate to those general factors which identify the positions as professional.

The degree of expertise required in a position to exercise assigned responsibility and accountability is a ranking factor. At the base level this factor equates to the basic academic qualification character upon which it rests. Before the expertise factor can be developed, therefore, it must include the variables of relevant in-service training, experience, professional activities, and further formal education. The addition of these variables, capable of quantitative and qualitative analysis, provides the means of raising this ranking factor through the continuum. The greater the quantity and quality of relevant expertise required by a position, the greater the value of that position to the organization and the higher the rank given to the position. In short, with respect to the quality of expertise, a basic principle of the approach developed in this paper is that the highest classification shall be reserved for those positions requiring the expertise necessary to exercise the broadest scope of responsibility and accountability.

This principle in no way conflicts with current management trends toward more participative "team approaches" in decision making and the implementation of library objectives. As responsibility and accountability are diffused throughout a system, expertise is at the same time diffused and increased and more positions will receive a higher ranking in this respect. Moreover, it should be stressed that management expertise is itself a legitimate form of professional expertise (albeit perhaps less recognized in libraries in terms of formal education than in many other types of institutions). Thus a position requiring advanced administrative expertise would rank high in terms of expertise, as would a position requiring advanced bibliographical and subject expertise.

The independence and freedom of action inherent in a position is a second ranking factor. The de facto "span of discretion," which is a quantitative temporal measure of the degree of independence and freedom which the organization can accord to a position, is a viable indicator of the level at which the position should be classified on the continuum.

The level of formal external contact which a given position requires to be ef- 
fective is a ranking factor in classifying the position. The importance of a subunit to the system of which it forms a part is largely determined by the degree of effective formal communication between the unit and the system. This is true whether the unit is a department of a library in communication with the library, or a library in communication with the parent body or system of which it is a part. Clearly, however, the importance of a communication is directly related to the expertise, the significance of error, and the span of discretion involved on the part of both the sender and of the receiver. Thus a necessary formal communication between a university president and member of a library staff has broader organizational implications (and hence more "importance") than has a similar communication between two subordinate positions. The responsibility for communication with the president inherent in a position places that position in a higher rank than that of a position charged with lower level communications.

Inherent in the level of formal external contact is the level of responsibility and accountability for any position, which can be determined qualitatively largely by the scope and depth of the responsibility involved and by the significance to the organization of an error made at the level of involvement in question. The greater the significance of error the higher the level of responsibility. In one sense, it is true, the significance of error reflects the positional impact upon the organization; but the stress is upon the degree of expertise required to avoid the error, as well as upon the hierarchical freedom from constraint. De facto rather than de jure responsibility and accountability assist in measuring the level of external contact.

Formal external contact is the ranking counterpart of the general factor of client relationships, the latter being, however, normally informal, self-initiated, and characteristic of all levels of professional performance. It is important to note, moreover, that formal external contacts must be necessary to the achievement of positional objectives in order to be considered a ranking factor, and that such contacts must demonstrably draw upon the appropriate level of expertise.

Planning and development form a ranking factor. The degree to which a position necessarily carries with it the need to plan and to develop programs is an indicator both of required expertise and of span of discretion. All professional positions should, as we have noted, require the use of judgment; but greater judgment in the use of comparative data is required in the development of programs than of tasks. Indeed, in terms of planning and development, stress should be laid as much upon the importance to the organization of the projects planned and upon their complexity as upon the planning and development activity itself. In assessing this factor, therefore, the distinction between tasks (which are normally single operations involving either repetition or a short span of discretion) and programs (which consist of the relating of a number of tasks) is important. The latter category presumably involves greater expertise, span of discretion, judgment, and significance of error.

Supervision is a ranking factor, though not if interpreted merely in terms of the number of personnel supervised. The number of individuals directly supervised by a position (span of control) is not an indicator or relative rank since the span of control normally shortens as the responsibilities of those supervised increases. The number of individuals indirectly supervised may, however, be of some value in assessing the rank of a position; but this criterion, in fact, relates more to the arbi- 
trary administrative scheduling of a hierarchical position than to its inherent value to the organization. Nevertheless, because this factor has quantitative value in a hierarchical system; because it will undoubtedly continue for some time to retain a traditional aura; and because it normally reinforces other ranking factors such as independence (span of discretion) and level of formal external contact (significance of error), supervision has some value in ranking a position.

\section{The Matrix}

The above four general and five ranking factors may be used to form the vertical axis of a matrix (Figure 1). The general factors do not appear as such on the vertical axis of the matrix because, although implicit in many of the ranking factors and though necessary to the "professional" nature of a position, they have little or no ranking capability. The five ranking factors do appear on the vertical axis, however, because they can be used to rank positions, although "supervision" may at times be regarded as "not applicable."

The horizontal axis of the matrix specifies the positions in the classification-Professional I, Professional II, Professional III, etc. The development of a ranking factor must be capable of being plotted along this horizontal axis (a necessary characteristic of any ranking factor since those factors operate on a continuum and can be divided horizontally at any number of convenient, and clearly defined, points). Thus, to take expertise as an example, it remains discretionary within the organization to determine "how much" expertise is required within one class of position and at what point on the continuum the expertise involved transcends a given class and raises the position in question to a higher class. Conceivably an organization could choose to incorporate only two classes of positions (or possibly only one), in which case the span of expertise demanded within each position class would be very wide. The only caveat to the above is, of course, that the lowest category of professional positions cannot include criteria "below" those specified in the description of the general factors which establish the professional nature of all positions.

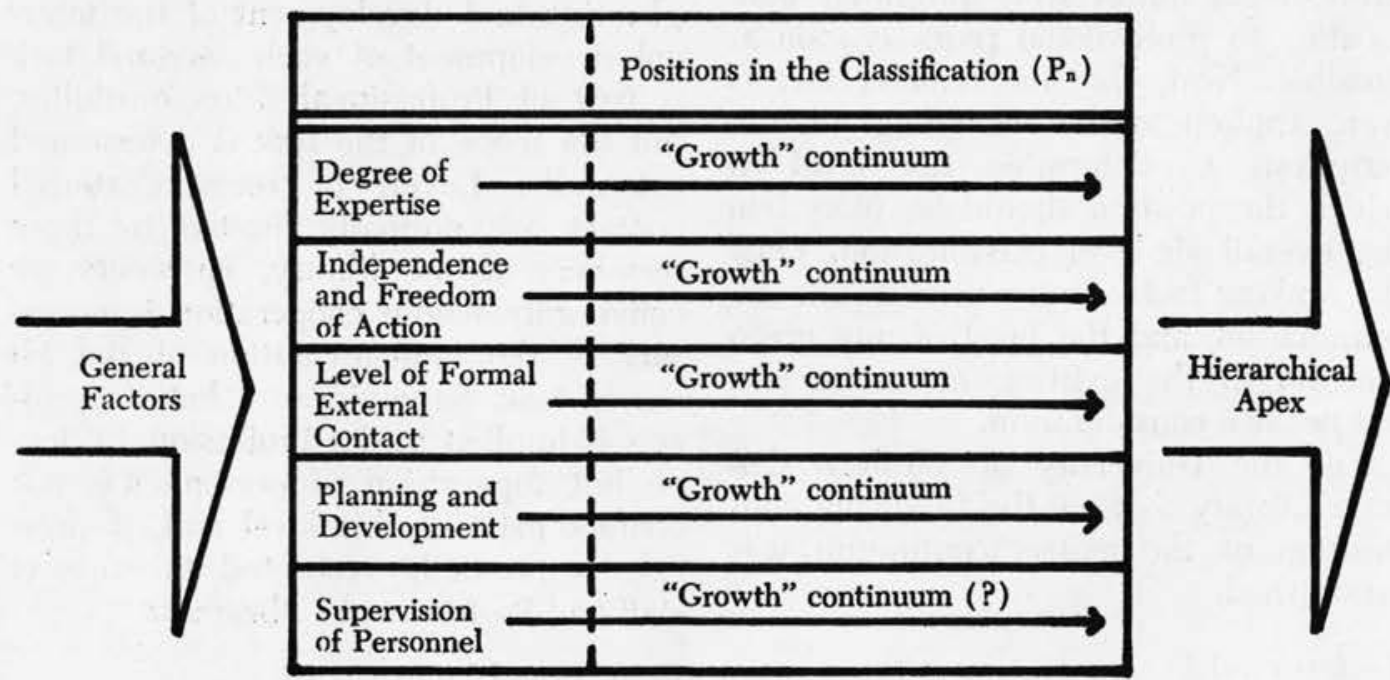

Fig. 1

The Position Classification Matrix 


\section{Application of the Matrix to THE UNIVERSITY OF WESTERN Ontario Library System}

The factorial principles underlying the matrix, when applied to the University of Western Ontario Library System, led to the development of the five ranking factors on a six-level continuum (Table 1). As has been indicated earlier, the four general factors in the schemata were used to determine the suitability of a post for inclusion as a professional position. The first task of the consultants was, therefore, to obtain job descriptions for all positions classified as "professional" by the UWO Library System, the questions pertaining to the descriptions being prepared and pretested by the consultants and the answers being supplied by the incumbent in conjunction with the relevant assistant director or department head. Those posts which could not, by application of the four general factors, be considered "professional" were then "declassified"; but it was made clear to the incumbents that the position and not the person was at issue. No individual was "demoted" because the position held was declassified, and professional librarians found to be performing nonprofessional duties were promised reallocation to professional posts as soon as possible. Next, the five ranking factors were applied to the remaining job descriptions to determine the level at which the position should be placed in the overall six-level classification. Only the ranking factors were used in this determination, and the level of any given position in the existing hierarchy was not per se a consideration.

For the University of Western Ontario Library System, the following codification of the matrix continuum was established.

\section{Professional 1}

This level predicates, as do all other levels, the four general factors-academic qualifications, judgments, client relationships, and voluntary involvement in professional activities-required for inclusion of a position in the schemata. However, grade 1 positions carry minimal responsibility and accountability, are subject to frequent supervision so that there is a minimal span of discretion, do not normally involve levels of formal external contact, do not involve primary responsibility for planning and development, and do not involve the supervision of professional personnel or independent projects. Professional 1 positions are professional positions and should not routinely include duties normally assigned to support staff; but this level is regarded as a stepping-stone or internship for higher levels and is not to be considered as a career grade.

\section{Professional 2}

This level, the first professional career grade, is characterized by a distinct though limited span of discretion and a demonstrable expertise. Positions in this grade carry with them the responsibility and authority for the implementation of a specific task or tasks, though the scope of the task(s) is limited. The planning and development of the internal development of each assigned task is part of Professional 2 responsibility, but the scope of the task is determined externally. Levels of formal external contact are normally limited to those members of the library, university, or community whose cooperation is necessary to the implementation of the assigned task. Supervision of limited projects is implicit at the Professional 2 level; but supervision of personnel is not characteristic of this level and, if present, is normally restricted to support staff and Professional 1 librarians.

\section{Professional 3}

This level is characterized by the 
strength of the supervision factor, either of projects or personnel. With respect to personnel, Professional 3 positions carry the responsibility for the direct supervision of support staff and of Professional 1 and 2 librarians who are normally the largest proportion of a library's personnel complement. Accountability is to a sharply decreased sector of the hierarchy, and span of discretion is correspondingly increased. Planning and development become relatively important at this level because of the necessity for integrating projects and personnel. Professional 3 positions are normally primarily concerned with internal administration; and formal external contacts, when present, are with the level of the library, university, and community which has decision-making functions. The degree of expertise required to exercise assigned responsibility and accountability at the Professional 3 level must be such that personnel or project units of complexity and considerable magnitude can be handled independently and successfully.

\section{Professional 4}

This level is characterized by the strength of the external contact factor. Professional 4 librarians are responsible for effectively presenting the library to policy advisory levels of the university and of the community and for assimilating external considerations into the library system. The degree of expertise necessary to meet this responsibility may be found either in management skills, highly developed professional competence, or specialized subject knowledge. Major project management not involving subordinate personnel, as well as the management of major personnel units, meets grade 4 requirements. The span of discretion for this level may be limited only by annual reports to Professional 5 or 6 personnel, and Professional 4 responsibility for planning and de- velopment may include the initiating of conceptual schemata.

\section{Professional 5}

This level is characterized by a responsibility for the broadest areas of homogenous activity and by direct accountability to sixth level positions. All ranking factors reach their culmination at Professional 5; and the general factors distinguishing professional positions should be present in an unusually high degree to develop fully the element of expertise. Supervision at this level is to be interpreted as coordination.

\section{Professional 6}

This level is characterized as the initial repository of the authority and responsibility delegated by the university to the library. Accountability at this level is to individuals or bodies external to the library. Professional 6 span of discretion is subject only to the regulations of the parent body, and the application of expertise rather than the expertise itself distinguishes this grade from the Professional 5 level.

\section{ADMINISTERING THE INSTRUMENTS}

The basic instruments in the application of the matrix discussed above to the professional staff of the UWO Library System were the codified matrix and the job description questionnaire. The codification was discussed fully with the UWO Library System administrative group in order to ensure that the application would realistically reflect any constraints of the UWO system. The administering of the questionnaire was equally carefully prepared for, both by the administrative group and by the consultants. As has already been indicated, the questionnaire was pretested and modified where necessary. The modifications were then discussed with the administrative group. An orientation session was held with the profes- 
TABLE 1

Classification for Professional Positions

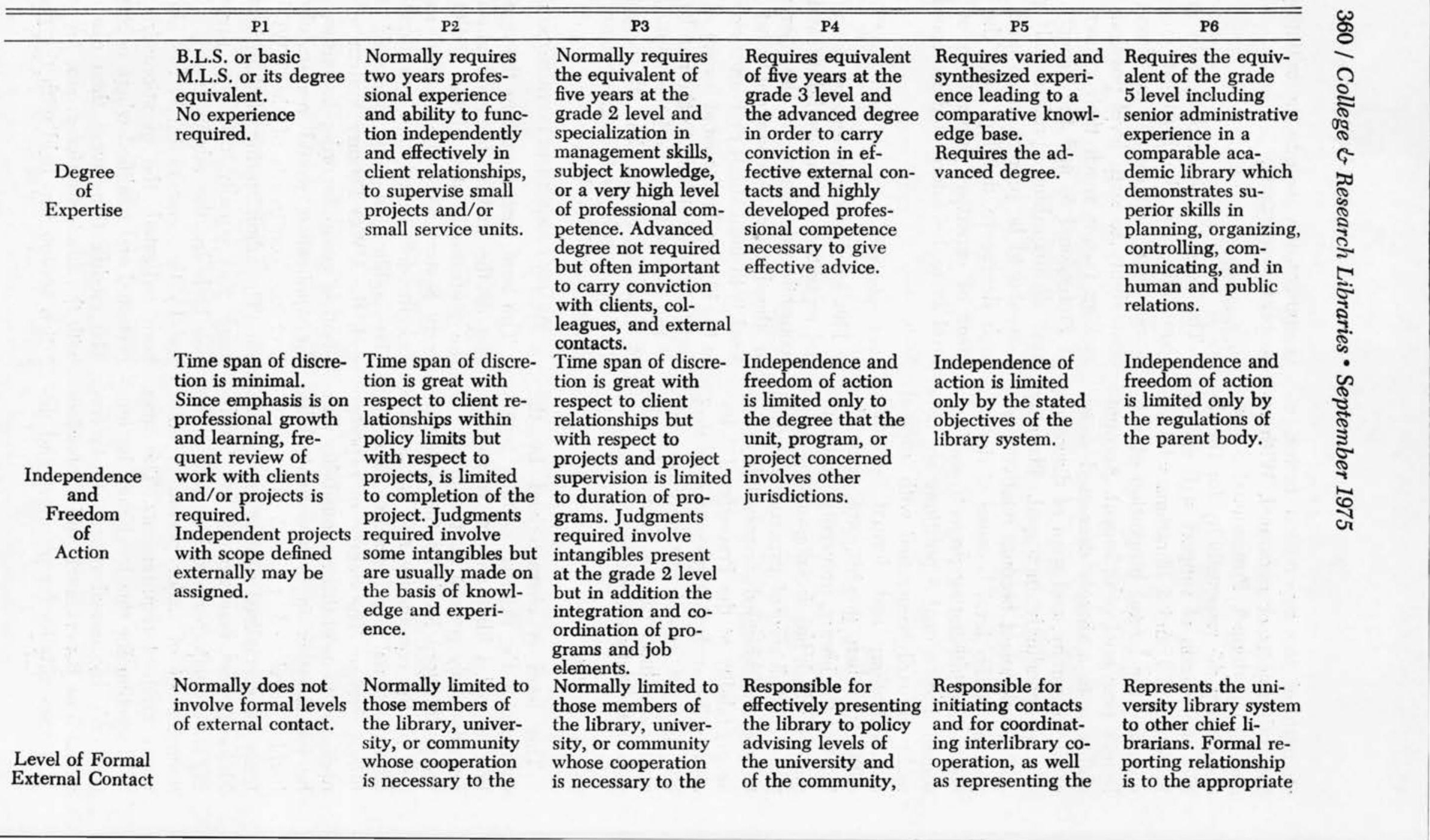



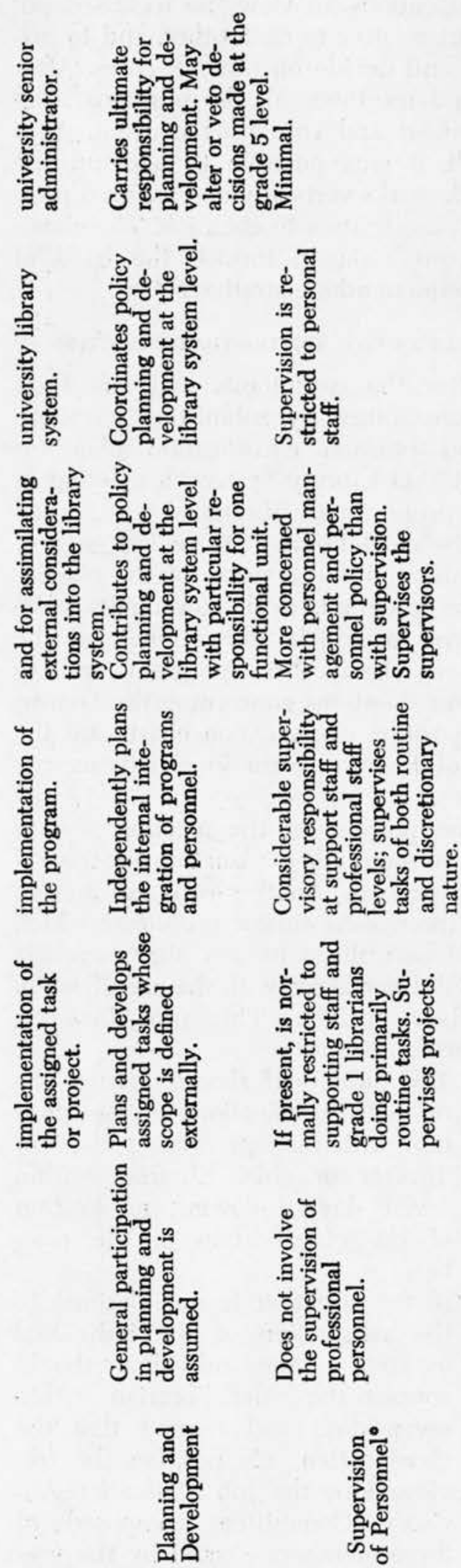

sional supervisors involved to ensure that the purpose of the questionnaire and the questions themselves were understood. Members of the UWO Library System professional staff were invited to meet individually with one of the consultants to discuss the filling out of the questionnaire, and a number of staff did so.

In addition to a summary job description, including percentages of time spent on principal duties, the following are selected examples from the twentythree item questionnaire:

Indicate the kind and level of educational requirements and professional experience necessary to perform effectively in your position. Why?

To what extent does your position require regular contacts with library personnel outside of your own department or unit? With university personnel outside of the university library?

Illustrate the types of problems which you are expected to deal with on your own and those which you would refer to a higher authority for solution.

Give an illustration of the type of long-range policy planning normally associated with your position.

Are the duties performed by the people you supervise primarily of a routine or of a discretionary nature? Give examples.

After all of the questionnaires had been filled out and approved by the supervisors, each consultant took a group of responses and analyzed them in terms of a grid profile sheet, composed of the four "general" and five "ranking" factors as shown in Table 1. The consultants then exchanged groups and conducted independent reevaluations. For most ranking factors there were at least three questions which dealt directly with each; but one factor, "supervision of personnel," was assessed in only two questions, and one factor, "degree of expertise," had nine questions specifically related to it. 
The use of the responses to several questions as "internal checks" in the plotting of ranking factors on individual profile sheets provided a cross-check on internal consistency; a means of "getting at" the factor in a variety of ways; and an elimination of any bias against a functional or service unit of the library that might have existed in any single question.

For each position, the question responses relating to each factor were analyzed and a check mark was placed in the appropriate box on the individual profile sheet. In cases where it was not clear how the presence of a factor should be ranked (e.g., whether or not a job ranked as a Professional 2 or Professional 3 according to a given factor), check marks were made in both boxes for the same factor.

The two consultants then compared their sets of profiles. In most cases agreement was achieved on the profiles. In those cases where disagreement occurred (usually because of ambiguous information in the response to the questionnaire) the profile was put aside for a discussion with the administrative group. In the course of the project, care was taken constantly to ensure that the objective was to rank jobs and not individuals. In this connection, one of the major problems identified was the tendency for respondents to view such elements as academic qualifications and experience in terms of their own achievements. The result was a variation in a factor such as "degree of expertise" among groups of librarians doing what appeared to be the same type of work. Because it was often unclear whether this variation was justified in terms of job requirements, these cases were noted for discussion with the administrative group. Other ambiguities and contradictions were handled in the same manner.

Next the consultants met with the library system administrative group to review the profiles and the preliminary classifications, to view the reclassed positions relative to each other, and to discuss and decide on difficult cases. After several meetings, all the positions were discussed and consensus reached. As a result it was possible to add up the check marks vertically and assign a position classification to each job. The classifications assigned formed the basis of subsequent administrative action.

\section{SubSEQuent Administrative ACtion}

After the consultants had met their responsibilities by submitting a rationalized position classification plan for the UWO Library System, a meeting of the professional librarians was called by the chief librarian to review each of the steps in the revision of the classification program. Both consultants were present to explain the rationale of the revised classification program and to answer questions concerning the factors, the position classification chart, and the use of the grid form in classifying positions.

One purpose of the meeting was to give a thorough explanation of the review process. Another was to present and discuss an appeal procedure which could be utilized by any staff members who did not agree with the classification of their position. This procedure includes four steps.

1. The individual should discuss the revised classification of the position with the appropriate assistant director or chief librarian within seven days following notification of the classification of the position.

2. If the situation is not clarified to the satisfaction of the individual in step 1, the individual should contact the chief librarian within seven days and request that the classification of position be reviewed by the Job Evaluation Advisory Committee, composed of three members elected by the pro- 
fessional staff, three assistant directors, and the chief librarian who serves as chairman.

3. The chief librarian reviews the recommendations and supporting documentation of each committee member, and makes a decision.

4. If the decision in step 3 is not acceptable to the individual, the staff member should contact the chief librarian and request that the position be reviewed by the university administration.

In several instances staff members indicated that the job evaluation questionnaire had not elicited a description of one or two unique features of their positions, or that they had neglected to provide detailed information on the questionnaire. As a result, the consultants were asked to interview the individuals who had expressed concern and to recommend any necessary changes.

The salary scale for the revised classification program includes five levels ( $\mathrm{Li}$ brarian I to Librarian V), with Librarian $\mathrm{I}$ as the entry point for beginning librarians without previous experience. The remaining four levels (Librarian II to Librarian V) are career grades. A minimum salary, which is externally competitive, is determined for each of the five levels. A maximum salary is stated for Professional 1 and 2, but salaries are open-ended for the remaining levels (Professional 3 through 6).

\section{Summary and Conclusion}

The purposes of the above classification program were, first, to determine the relative value of each position in relation to other professional positions with the aim of achieving internal consistency; second, to evaluate each position and not the individual holding the position or the individual's performance of the position; and, third, to develop an externally competitive salary scale. Consultants and library staff learned a great deal, including the difficulty of achieving internal consistency, of trying to separate the person from the position, and of recognizing individual differences and perceptions.

Each academic library is constantly changing: the organizational arrangement is continually modified; the level of expertise and responsibility for professional positions alters from time to time. The classification of professional positions must, therefore, be reviewed continuously and kept up to date as positions change in order to keep pace with changing needs and requirements. This paper has provided a case study of one such library's attempt to keep pace in terms of a rational position classification-acceptable to the library's community as a whole and justifiable to the library's professional personnel.

\section{REFERENCES}

1. Leslie Beth Rothenberg and others, "A JobTask Index for Evaluating Professional Utilization in Libraries," Library Quarterly 41: 320-28 (Oct. 1971).

2. Myrl Ricking and Robert E. Booth, Personnel Utilization in Libraries: A Systems Approach (Chicago: American Library Assn., 1974).

3. Robert B. Downs and Robert F. Delzell, "Professional Duties in University Libraries," College \& Research Libraries 26:30-39 (Jan. 1965).

4. Marjorie Tompkins, "Classification Evaluation of Professional Librarian Positions in the University of Michigan," College \& Research Libraries 27:175-84 (May 1966).

5. Ibid., p.176.

6. David W. Belcher, Compensation Administration (Englewood Cliffs, N.J.: Prentice Hall, 1974), p.145.

7. Tompkins, "Classification Evaluation," p. 182. 